\title{
Emprendimientos académicos sobre la base de I+D
}

\author{
Mario Alberto Morel Barahona ${ }^{1}$
}

En los procesos económicos y empresariales actuales convergen múltiples factores que generan desarrollo y crecimiento a las naciones que visualizándolos desde la perspectiva de las tecnologías de la información, se asemejan a dos sistemas expertos, los cuales mediante un motor de inferencia son capaces de modelar el razonamiento humano, capturando el conocimiento tácito y convirtiéndolo de datos en bruto a información procesada y útil para sus usuarios.

Estos sistemas poseen una cantidad innumerable de dispositivos con una función especializada que constantemente alimentan, comunican e interactúan con los sistemas, con el fin de compartir recursos y generar nueva información. Dentro de estos sectores existen actores que se asemejan a los sistemas expertos, a tales actores se les identifica como emprendedores, quienes por medio de sus iniciativas generan los insumos catalizadores de la dinámica constante que estos sectores poseen en beneficio del país.

El concepto de emprendedor se deriva del francés "entrepreneur", el cual se ha convertido en el término que denota a la persona con las actitudes o aptitudes suficientes para convertir una idea en un producto, proceso o servicio, con un valor agregado capaz de satisfacer una necesidad existente en la sociedad. El emprendedor ha sido el objeto de múltiples estudios en distintos campos del conocimiento, desde cómo desarrolla sus procesos cognitivos al momento creativo de generar sus ideas, hasta como este se desenvuelve en sus ámbitos de acción.

No obstante las expectativas que suscitan los emprendedores, para ser creativo no se necesita tener el intelecto de una persona prodigio para ser merecedor de esa denominación, cualquier persona es capaz de realizar iniciativas en su campo; pues para emprender solamente es necesario el deseo, esfuerzo y disciplina, sumado a la identificación de una oportunidad en donde su idea pueda insertarse.

En consecuencia, las acepciones sobre un emprendedor son variadas, ya que su

1 Departamento de Propiedad Intelectual e Innovación, Dirección de Investigación Científica y Posgrado, UNAH: investigacionunah.pi.innov.mm@gmail.com 
accionar no se limita al ámbito empresarial, de modo que se pueden reconocer diferentes tipos de emprendedores según el área donde se desempeñen; pero, en este contexto académico, el emprendedor se caracteriza por desarrollar sus esfuerzos y generar sus iniciativas tomando como nutriente primordial los insumos producidos a partir de la $\mathrm{I}+\mathrm{D},{ }^{2}$ a este proceso le denominamos: emprendimientos académicos.

Así, el tipo de emprendedor que surge en el seno de la universidad es aquel que posee una formación académica en una disciplina determinada del conocimiento y que total o parcialmente su carrera se ha visto vinculada a la investigación; se identifica como un catalizador importante para que los resultados de investigación obtengan el o los elementos necesarios para convertirse en productos, procesos 0 servicios con un valor agregado de conocimientos producto del proceso de investigación y desarrollo. Los emprendedores identificados en este ámbito son profesores o estudiantes que han adoptado la investigación dentro de su accionar académico, haciendo énfasis en que estas acciones enmarcadas en la investigación buscan ser de utilidad a la sociedad y ser monetizables.

En tal contexto, la finalidad de los emprendimientos a cargo de los investigadores, dentro de la academia, se centra en el nuevo paradigma de la universidad emprendedora, en donde la tradicional actividad de docencia e investigación -dos de las tres misiones fundamentales de toda universidad- incorpora un accionar fuertemente ligado al sector productivo mediante la tercera misión que conocemos como vinculación o extensión.

Sobre este punto, las grandes universidades a nivel mundial, pioneras en el accionar intensivo de este rol académico, han demostrado con grandes éxitos en sus resultados cómo el conocimiento producto de la I+D es capaz de beneficiar a la población, cuando estos toman la figura de productos, procesos o servicios; asimismo brinda al país un impulso económico importante en su desarrollo y, otro punto a favor, proveen a la universidad una vía para la generación de insumos que propicien sustentabilidad al proceso y beneficios económicos a la institución, teniendo siempre como visión primordial el aporte científico a la sociedad, más que un fin meramente lucrativo.

2 I+D: es el símbolo para identificar la vinculación entre investigación y desarrollo que se aplica a los departamentos de investigación, públicos o privados, enfocados en el desarrollo de nuevos productos, procesos o servicios, o bien, la mejora de los ya existentes. 
Otra característica de la I+D es que engloba múltiples actividades como crear, utilizar, aplicar y explotar el conocimiento en ambientes no académicos y transforma los resultados de la investigación básica en aplicaciones con un retorno económico, en lugar de la sola producción de conocimiento (investigación académica) y transmisión del mismo (publicaciones y docencia). Pero, también contiene inmersos retos para la armonización con las otras misiones de la universidad, al establecer un vínculo más estrecho con el sector productivo.

En el ámbito regional, las acciones por parte de las principales universidades han logrado grandes avances en el establecimiento de las rutas a seguir y los medios más adecuados para que la producción de I+D en las academias, de manera que logren alcanzar su finalidad de utilidad y monetización. Al respecto, muchos estados ya se encuentran flexibilizando y adecuando sus normativas para propiciar escenarios beneficiosos al accionar universitario y empresarial; estos, a su vez, se convierten en actores importantes al ser los entes que definen, establecen y regulan las condiciones en que se desarrollarán los procesos en estos escenarios.

En nuestro ámbito los procesos de ciencia y tecnología se encuentran inmersos en un estado en donde la publicación de un artículo científico es un fin idóneo para el conocimiento generado, sin brindar mayores aportes a la sociedad. Sin embargo, en la mayor casa de estudios del país ya se pueden identificar acciones enfocadas a que este conocimiento científico pueda convertirse en un bien tangible, de forma que los esfuerzos se orientan hacia una estrategia de innovación trazada en la línea de las tendencias internacionales, la cual ha venido estableciendo las bases en la institución para comenzar a recorrer seriamente la ruta de la transferencia tecnológica y reconvertir su modelo tradicional basado en docencia, en un modelo de universidad emprendedora.

Partiendo de lo anterior, es posible cuestionamos por qué los investigadores deben pensar en transferir sus tecnologías. La respuesta apunta a que todos estos emprendimientos generados como resultados de la actividad de I+D en la academia, deben buscar una vía para llegar a la sociedad y beneficiarla mediante su uso, adopción y aprovechamiento; de lo contrario serán parte de los cúmulos interminables de datos almacenados que cumplen el único fin de alimentar una estadística inútil en los registros institucionales, convirtiéndose en un gran desperdicio de recursos y un atraso en el desarrollo del conocimiento.

Lo anterior refiere a lo que se conoce como la transferencia tecnológica, que es la vía 
que a nivel mundial las universidades están adaptando y adoptando para que sus investigadores puedan llevar sus emprendimientos a la sociedad; pero, esto plantea la interrogante sobre qué mecanismos hacen posible que los resultados de I+D puedan ser transferidos a la sociedad. En el caso de la academia, a nivel mundial, el medio más adecuado hasta ahora son las empresas universitarias de base tecnológica, también conocidas como "spin-off", las cuales constituyen el mecanismo apropiadopara validar y madurar soluciones tecnológicas producto de la investigación aplicada y representan la ruta emprendedora para la monetización de los activos intangibles (inmersos en productos, procesos y servicios).

Estos mecanismos son instrumentos empleados por las grandes universidades para dotar al país de insumos para su desarrollo; consecuentemente, los emprendimientos académicos de las universidades pueden hacer uso de esta herramienta empresarial para alcanzar avances significativos en el progreso de la ciencia y la tecnología, ya que la finalidad de estas empresas consiste en valorizar el conocimiento científico y tecnológico de la institución y poder explotar estos resultados de investigación alcanzando beneficios económicos socialmente responsables.

No obstante, el establecimiento de este tipo de empresas universitarias de base tecnológica no es un proceso que pueda ser realizado solamente por el mismo investigador, este debe considerar múltiples factores determinantes para el éxito de las mismas, entre ellos el hecho de que generalmente el investigador no suele poseer las habilidades necesarias para llevar las riendas de la empresa y continuar desempeñándose en sus actividades de investigación, lo cual se convierte en una disyuntiva para su persona, puesto que obliga a tomar la decisión de ser un empresario 0 un investigador. Si se decide por el camino empresarial debe contar con la asesoría pertinente durante cada etapa del proceso, ya que el proceso involucra múltiples actividades empresariales de mercadeo, negociación, legales y financieras, entre otras. Debido a lo anterior los investigadores deben, en la estrategia de creación del emprendimiento sobre la base de I+D, contar con la participación de expertos en gerencia de empresas y la asesoría necesaria para minimizar el riesgo del fracaso.

En este aspecto, la academia es la llamada a brindar los medios para que sus investigadores emprendedores puedan recorrer la senda hacia la explotación de resultados con las mayores condiciones favorables y las garantías necesarias para que en el desarrollo del proceso se posean los medios y los recursos necesarios para 
la consecución efectiva de sus objetivos. Un caso de éxito en este tema es la Universidad Sains de Malasia (USM), la cual posee un ecosistema de innovación consolidado que proporciona a los investigadores las distintas herramientas para el establecimiento de sus iniciativas como empresas en el seno de la universidad, asimismo ha forjado una estrategia para generar las condiciones favorables para que estos mecanismos sean atractivos y viables en su uso por parte de sus actores académicos vinculados a investigación.

La USM en su accionar dentro de la transferencia de conocimientos científicos y tecnológicos a la sociedad, posee una oficina encargada de ser el eslabón principal en el vínculo de la academia con la empresa, la cual cuenta con recurso humano especializado con las habilidades necesarias para identificar en la sociedad las necesidades tecnológicas que pueden ser cubiertas por medio de la investigación generada en su entorno académico; de igual manera, en un proceso inverso, se encarga de vigilar el entorno exterior a la academia para transmitirle las oportunidades existentes en donde el conocimiento científico y tecnológico puede aprovecharse y ser de gran utilidad.

Todo lo antes expuesto significa que la propiedad intelectual se ha convertido es un factor importante en este proceso, ya que los resultados de I+D deben tener un riguroso análisis que determine la mejor vía de protección: patente, secreto industrial, modelo de utilidad, etc. De estos se derivan el derecho de autor y la propiedad industrial, que son las categorías que enmarcan las distintas figuras a las que el investigador puede optar para la protección de los activos de autoría o creatividad.

En el ámbito de los emprendimientos académicos sobre la base de $\mathrm{I}+\mathrm{D}$, la propiedad intelectual provee los mecanismos adecuados para la protección de las tecnologías por medio de un inventor, ${ }^{3}$ pero este desconoce los procesos legales y debe asesorarse correctamente acerca de las figuras de protección por propiedad intelectual, la cual estratégicamente puede generar los mayores retornos a la institución por su producto, proceso o servicio generado.

En síntesis, los emprendimientos académicos sobre la base de I+D son la respuesta a la tendencia mundial que las universidades siguen al vincularse con el sector empresarial, nexo que trae consigo múltiples beneficios para ambos; lo cual es mejor que continuar desenvolviéndose aisladamente. Este nuevo contexto en la era

3 Individuo que idea, crea, concibe algo que no existía antes o proporciona una mejoría única al mismo. 
tecnológica hace pensar en que los individuos trabajando en sus laboratorios aisladamente para generar innovaciones rupturistas, ${ }^{4}$ como los clásicos inventores (Tesla, Franklin, Da Vinci, etc.), ya no tienen cabida, puesto que esta nueva visión de los emprendedores académicos conlleva un nuevo paradigma que exige el involucramiento, la vinculación y trabajo en equipo para generar redes de intercambio y producción de conocimiento en beneficio de la sociedad y el desarrollo de país.

En el caso de la UNAH, ${ }^{5}$ como uno de los máximos referentes en investigación en el país, deben llevarse a cabo acciones que permitan construir una cultura emprendedora sobre la base de I+D, estableciendo a su vez alianzas con la sociedad, la empresa, el sector público, la comunidad de cooperantes y especialmente con otras universidades y centros de investigación para fortalecer la formación del recurso humano, la infraestructura de ciencia y tecnología, pero sobre todo la visión sobre el papel de la universidad en el desarrollo social y económico de Honduras.

4 Se considera como innovación rupturista al producto, proceso o servicio que posee características totalmente nuevas y nunca antes vistas en su área.

5 Siglas de la Universidad Nacional Autónoma de Honduras. 